\title{
Relax rights to human genes
}

\section{The time has come to reassess the benefits of the present practice of patenting human genetic material.}<smiles>C1CC2CCCC2C1</smiles>
atients' rights advocate groups, academic researchers and societies, and public hospitals around the world are in an uproar over some consequences of the patenting of human genes.

As unbelievable as it may sound, approximately $20 \%$ of the human genome is under patent in the United States. Thousands of genes are covered by similar patents in Europe, Australia and other developed countries. Although the first gene patents were issued in the 1980s, controversy still swirls over the issue of whether the DNA that constitutes a gene or a mutation therein is actually patentable. Originally intended to provide an incentive for innovation, patents are typically issued for new inventions. In response to the question of whether genes and mutationswhich exist naturally in the human body - can rightly be considered 'inventions', the US Patent and Trademark Office declared that "an inventor's discovery of a gene can be the basis for a patent on the genetic composition isolated from its natural state and processed through purifying steps that separate the gene from other molecules naturally associated with it." Many geneticists view this logic, which implies that because cDNA does not exist in nature, it qualifies as an invention, as a loophole based on a technicality. Even if this logic were to be accepted, would the patent not then apply only to the cDNA, not the actual gene itself?

Philosophical issues aside, recent events have identified more urgent and practical problems associated with gene-patenting practices. Specifically, some patents for disease-associated genes and mutations, when used to secure exclusive licensing arrangements, drive up the cost of diagnostic testing.

In the United States, where the Salt Lake City-based company Myriad Genetics holds broad patents covering BRCA1 and BRCA2, a screen for mutations in these genes-which are associated with a considerable increase in the risk of breast and ovarian cancer-costs over US $\$ 3,000$. In Europe, where the Myriad patent on BRCA1 was revoked in 2004, a similar test runs at US $\$ 1,900$. After a long legal appeal of the patent revocation, in November 2008 the European Patent Office granted Myriad a narrower patent covering only diagnostic screens for frameshift mutations in BRCA1. Although viewed by many researchers and clinicians as a partial victory against the overly broad patent claims and high licensing fees imposed by Myriad, the decision does not clarify whether screens designed to identify all mutations (for example, including frameshift mutations) will nevertheless be deemed as infringing the remaining Myriad European patent. When called on to justify the high price of the US test, Myriad cited the fact that most US insurance companies view the test as cost-effective and therefore cover it. Unfortunately, the test will probably be unaffordable and thus out of reach to a large subset of the ever-growing number of uninsured people in the United States. Whether government -run health -care systems in Europe will be willing to cover the high cost of the test remains unclear.

In Australia, the Melbourne-based company Genetic Technologies holds a patent on SCN1A, a gene whose sequence is altered in children with Dravet syndrome, an extremely severe form of epilepsy. Accurate diagnosis of Dravet syndrome, which requires a genetic screen of SCN1A, must be done early, as erroneous prescription of standard epilepsy drugs can worsen the prognosis for children with the more severe Dravet syndrome. Fortunately, public hospitals are willing to do SCN1A screens 'inhouse'. However, Genetic Technologies recently barred public hospital testing on the grounds of patent infringement. Rather than risk litigation or pay the costly royalties now imposed by Genetic Technologies, public hospitals are sending DNA samples to Europe for testing. Neurologists say that as a result of the high cost of the European test-which equals the price of the Genetic Technologies test—-fewer children are being screened.

Fortunately, governments are responding to the outcry over these incidents. In the United States, the Department of Health and Human Services convened a panel to weigh the positive and negative effects of gene patenting. In a preliminary statement, the Health and Human Services committee indicated that broad gene patenting and exclusive licensing arrangements may hinder the future development, commercialization and affordability of whole-genome screens, viewed by many to hold even more predictive power than the now widely available singlenucleotide polymorphism screens. Companies offering single-nucleotide polymorphism screens are already scrambling to devise creative ways to pay royalties as a result of patents on single-nucleotide polymorphisms or genes while still retaining some kind of profit margin. In addition, in February 2007, a bipartistan team of the US Congress introduced the Genomic Research and Accessibility Act, designed to prohibit the patenting of human genetic material, to the US House of Representatives. When and if the bill will pass remains to be seen.

In Europe, the European Society of Human Genetics recently completed a study of the public health consequences of gene patents. Concluding in a summary report that excessively broad patent claims "negatively impact development," they recommended modifying but not abolishing gene patents. Suggested modifications included the establishment of a system to facilitate voluntary reporting by geneticists and/or clinicians of incidents in which gene patents impinge on public access to diagnostic services, the adoption of more narrow patent claims, the formation of a committee to consider ethical interests in the granting of gene patents, and the exploration of alternative forms of affordable and, in some cases, compulsory licensing arrangements.

Recent litigation and inquiries indicate that the issue of gene patenting has grabbed the attention of governments around the world. Whether narrowed or abolished altogether, gene patents and their associated licensing arrangements must be altered to ensure that they stimulate rather than stifle scientific research and facilitate rather than restrict public access to advancing clinical technology. 